\title{
Safety and sedative effect of intranasal dexmedetomidine in mandibular third molar surgery: a systematic review and meta-analysis
}

This article was published in the following Dove Medical Press journal:

Drug Design, Development and Therapy

\author{
Shaopeng Liu',2,* \\ Ye Wang ${ }^{1,2, *}$ \\ Yong Zhu ${ }^{1,2}$ \\ Tingting $\mathrm{Yu}^{3}$ \\ Huaqiang Zhao ${ }^{1,2}$ \\ 'Shandong Provincial Key Laboratory \\ of Oral Tissue Regeneration, School \\ of Stomatology, Shandong University, \\ Jinan, Shandong 2500 I 2, People's \\ Republic of China; ${ }^{2}$ Department of \\ Oral and Maxillofacial Surgery, School \\ of Stomatology, Shandong University, \\ Jinan, Shandong 2500 I 2, People's \\ Republic of China; ${ }^{3}$ Department \\ of Oral and Maxillofacial Surgery, \\ Jinan Stomatological Hospital, Jinan, \\ Shandong 2500 I2, People's Republic \\ of China \\ *These authors contributed equally \\ to this work
}

Objective: The focus of this meta-analysis was to assess the sedative effect and safety of intranasal dexmedetomidine (Dex) in mandibular third molar surgery.

Methods: The PubMed/Medline, Web of Science, Cochrane Library, and China National Knowledge Infrastructure databases were searched for studies published until May 1, 2018. Eligible studies were restricted to randomized controlled trials (RCTs) and controlled clinical trials. The evaluation indicators mainly included the bispectral index, observer assessment of alertness/sedation scale, systolic blood pressure, and heart rate. Data for each period in the Dex and control groups were pooled to evaluate its sedative effect and safety.

Results: Five RCTs met the inclusion criteria. This study included 363 patients: 158 patients received intranasal inhalation of Dex before surgery, and 158 patients were negative controls. The pooled results showed a good sedative effect during tooth extraction when intranasal inhalation of Dex was performed 30 minutes before third molar extraction (assessment of alertness/ sedation, Dex vs control SMD $-1.20,95 \% \mathrm{CI}-1.73$ to $-0.67, I^{2}=0, P=0.95$; bispectral index, Dex vs control SMD $-11.68,95 \%$ CI -19.49 to $-3.87, I^{2}=89 \% ; P=0.0001$ ), and parameters returned to normal within 90 minutes after inhalation. During the operation, blood pressure and heart rate decreased to some extent, but the decreases did not exceed $20 \%$ of the baseline, and all patients returned to normal conditions within 90 minutes after inhalation.

Conclusion: Intranasal inhalation of Dex 30 minutes before third molar extraction can provide a good sedative effect, and large-sample multicenter RCTs are needed to evaluate the analgesic effect of Dex.

Keywords: intranasal dexmedetomidine, sedation, mandibular third molar, meta-analysis

\section{Introduction}

Mandibular third molar extraction is a common procedure in the oral and maxillofacial region. ${ }^{1-3}$ Patients often have a high degree of fear and anxiety when facing toothextraction surgery. ${ }^{4}$ Many factors may cause or increase the preoperative nervousness or anxiety of patients. Common factors are visual (tooth extraction instruments, including various sharp needles and elevators), pain perception (pain when injecting anesthesia, discomfort when cutting tooth tissue, prolonged intraoperative mouth-opening time), auditory (sound of the high-speed air-turbine drill when cutting tooth tissue), and previous unpleasant dental treatment experience. ${ }^{5-7}$

Dexmedetomidine (Dex) is a highly selective $\alpha_{2}$ adrenergic receptor agonist that triggers and maintains natural sleeping status without eye movement by stimulating the locus coeruleus in the brain stem, which is the densest region of $\alpha_{2}$ receptors in the central nervous system. ${ }^{8,9}$ It produces sedative and hypnotic effects, and patients in 
this sedative state can be aroused by stimulation or language. Respiratory depression does not occur during the process of sedation. ${ }^{10}$ Dex is being used commonly in various specialties like surgery, anesthesiology, critical care medicine, neurosurgery, and dentistry for its anti-inflammatory and sedative effects. ${ }^{11-14}$ Intravenous injection is the standard method of Dex administration. ${ }^{10,15}$ However, studies have shown that intranasal inhalation of Dex can also produce good sedative effects, and the drug is widely used for general anesthesia induction in children. ${ }^{16,17}$ In recent years, some oral surgeons have evaluated the analgesic effect of intranasal inhalation of Dex during third molar surgery, but the results have not been consistent.

A literature search confirmed that no relevant metaanalysis had been conducted to evaluate systematically the sedative effect of intranasal inhaled Dex during the extraction of wisdom teeth. Moreover, a consensus has not been reached regarding the analgesic effect of Dex. Therefore, the purpose of this systematic review was to evaluate systematically the analgesic efficacy and safety of intranasal inhalation of Dex in third molar surgery and provide theoretical support for its subsequent clinical application.

\section{Methods}

\section{Search method}

All studies that evaluated and compared the sedative and analgesic effects of intranasal inhalation of Dex and a control group undergoing mandibular third molar surgery were included in this study. We searched the PubMed, Web of Science, Cochrane Library, and China National Knowledge Infrastructure (CNKI) databases for literature published before May 2018 (Supplementary material). To ensure that the included literature was comprehensive, citations and related reviews were manually retrieved.

\section{Inclusion and exclusion criteria}

Studies had to meet the following criteria: randomized controlled trial (RCT), no language restriction, comparing the sedation and analgesic effects of Dex with placebo after third molar surgery in humans, and sufficient original outcome data to calculate standardized mean difference (SMD) or WMD with corresponding 95\% CI. Inclusion criteria also included animal studies, case reports, in vitro studies, and reviews.

\section{Quality assessment}

Quality assessment of the included studies was determined according to the Cochrane Collaboration tool, which comprises seven criteria: random sequence generation, allocation concealment, blinding of participants and personnel, blinding of outcome assessment, incomplete outcome data, selective reporting, and other bias. ${ }^{18}$

\section{Data extraction}

Two authors independently extracted the data based on a previously designed data extraction table. Data extracted were author, country, experimental design, impaction type, age, operative time, and dose and evaluation indicators.

\section{Statistical analysis}

To assess the safety and sedative of intranasal Dex in mandibular third molar surgery, pooled WMD or SMD with corresponding $95 \%$ CI was calculated. Due to the variety of measures and different units used, SMD was employed. ${ }^{19}$ The level of statistical heterogeneity among studies was qualitatively and quantitatively assessed through Cochran's $Q$ test and $I^{2}$ statistic, respectively. ${ }^{20}$ When $I^{2}<50 \%$, a fixedeffect model was used. Otherwise, a random-effect model was used. To compare characteristics of subjects, interventions, and clinical outcomes among included studies, clinical heterogeneity was assessed. ${ }^{21}$ Methodological heterogeneity was determined with the Cochrane risk-of-bias tool. ${ }^{18} \mathrm{By}$ omission of study data sequentially, a sensitivity analysis was implemented to explore potential intergroup heterogeneity. Funnel plots were used to evaluate publication bias. ${ }^{22}$ All statistical analyses were implemented using RevMan 5.3 (Nordic Cochrane Center, Copenhagen, Denmark). Twosided $P<0.05$ was regarded as statistically significant.

\section{Results \\ Study inclusion}

Screening of the articles followed PRISMA principles, and the study inclusion process is shown in Figure 1. In the initial search, eleven articles were retrieved from PubMed, 18 from Web of Science, and 13 articles from the Cochrane Library. A total of 22 articles were excluded, due to duplication, Dex not being applied, or Dex not being applied for third molar extraction. For the remaining 14 articles, after examination of full texts, ten were excluded (Figure 1). In addition, one article retrieved from the CNKI database was included. Finally, five articles were included in this systematic review (Table 1). ${ }^{23-27}$ This study included 363 patients: 158 patients received intranasal inhalation of Dex before surgery, and 158 were negative controls. All articles were published between 2011 and 2016. Of the five articles included, except for Cheung et al (1.0 mg/kg dose of Dex), ${ }^{26}$ four used a $1.5 \mathrm{mg} / \mathrm{kg}$ dose of Dex. ${ }^{23-25,27}$ Regarding Dex-induction time, in four articles patients were injected with local anesthetic drugs 30 minutes after intranasal inhalation of Dex..$^{23,25-27}$ After 

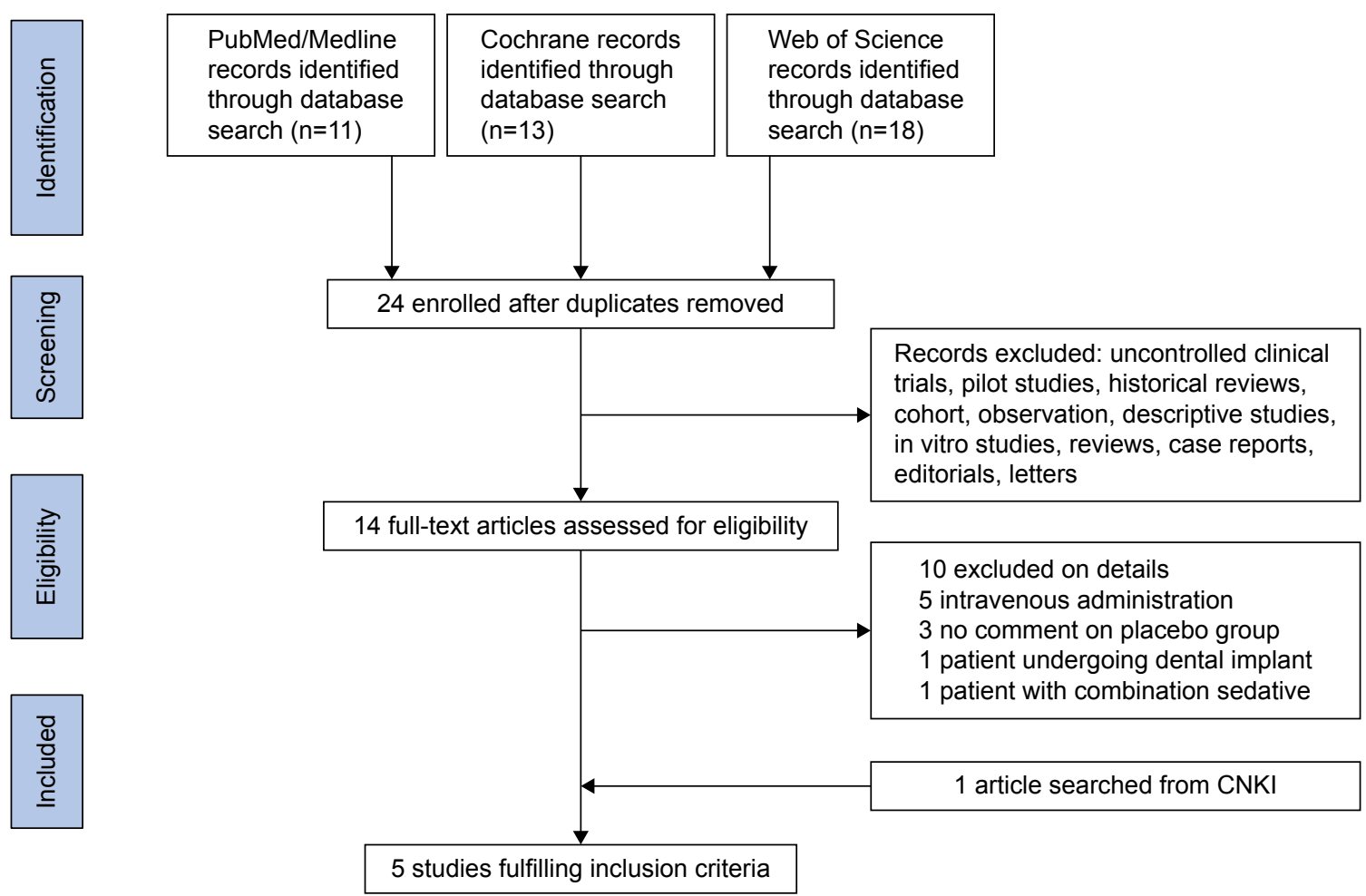

Figure I Study selection process.

Abbreviation: CNKI, China National Knowledge Infrastructure.

a sufficient anesthesia effect had been achieved, the third molar was removed. In one article, a local anesthetic drug was injected 20 minutes after intranasal inhalation. ${ }^{24}$ The results of the bias analysis are shown in Figure 2.

\section{Observer assessment of alertness/ sedation scale}

The patient's degree of sedation was assessed by an observer using a modified observer assessment of alertness/sedation $(\mathrm{OAA} / \mathrm{S})$ score and recorded every 10 minutes. Three articles recorded OAA/S values ${ }^{23,25,27}(0-5$ or $0-6)$, and SMD was determined. Compared to the control group, sedation occurred after 20 minutes in the group with intranasal inhalation of Dex (Dex vs control, SMD -1.20, 95\% CI -1.73 to $\left.-0.67, P^{2}=0 ; P=0.95\right)$. The peak of sedation was reached at 40 minutes (Dex vs control, SMD $-3.19,95 \% \mathrm{CI}-3.95$ to $-2.43, I^{2}=0 ; P=0.42$ ), and the basal level was restored after 80 minutes (Dex vs control, SMD $-0.65,95 \%$ CI -1.43 to $0.14, I^{2}=65 \% ; P=0.12$; Table 2).

\section{Bispectral index}

The bispectral index (BIS) is a number that represents mixed information obtained by analyzing the power and frequency of electroencephalography. BIS scores range $0-100$, and larger values represent increased consciousness of the patient. A BIS value of $85-100$ is generally considered normal, $65-85$ sedated, $40-65$ anesthetized, and a value $<40$ may result in burst suppression. ${ }^{28}$ Three articles included in this study evaluated sedation using BIS indicators recorded every 10 minutes. ${ }^{24-26}$ Pooled results showed that BIS values of the two groups were significantly different 20 minutes after intranasal inhalation (Dex vs control, MD -6.03, 95\% CI -7.78 to $\left.-04.27, I^{2}=0 ; P=0.84\right)$. The difference in BIS values between the two groups was greatest at 40 minutes after intranasal inhalation (Dex vs control, MD -11.68, 95\% CI -19.49 to $\left.-3.87, I^{2}=89 \% ; P=0.0001\right)$. At this time, the Dex group had reached an obvious sedative state. At 90 minutes after intranasal inhalation, no significant difference in BIS values was observed between the two groups, indicating that the Dex group had returned to the basal level (Dex vs control, MD $-5.14,95 \%$ CI -18.99 to $8.70, I^{2}=97 \% ; P<0.00001$; Table 3).

\section{Heart rate}

Three articles included in this study recorded the heart rate (HR) of patients. ${ }^{25-27}$ Pooled results showed that HR was 6.68 beats/minute lower than that of the control group 30 minutes after intranasal inhalation of Dex (Dex vs control, MD -6.68 beats/minute, $95 \%$ CI -11.55 to -1.80 , $\left.I^{2}=71 \% ; P=0.03\right)$. The difference was greatest at 40 minutes after intranasal inhalation, when HR in the Dex group was 10.82 beats/minute lower than that of the control group 


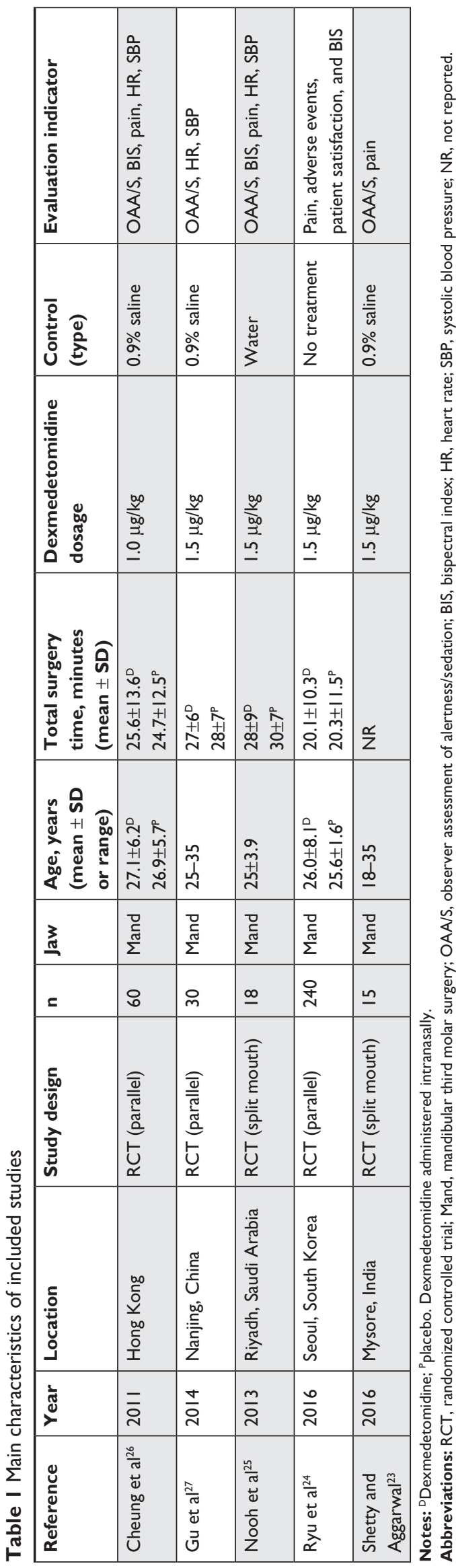

(Dex vs control, MD -10.82 beats/minute, $95 \%$ CI -13.20 to $\left.-8.43, I^{2}=45 \% ; P<0.16\right)$. No significant difference was observed in HR between the two groups at 90 minutes after intranasal inhalation, suggesting that patients had returned to baseline (Dex vs control, MD $-3.19,95 \%$ CI -7.32 to 0.94 beats/minute, $I^{2}=66 \% ; P=0.05$; Table 4 ).

\section{Systolic blood pressure}

Three articles included in this study recorded patients' intraoperative blood pressure. ${ }^{25-27}$ Pooled results showed that 30 minutes after inhalation of Dex, blood pressure was $7.47 \mathrm{mmHg}$ lower than the control group, and the difference was statistically significant (Dex vs control, $\mathrm{MD}-7.46 \mathrm{mmHg}$, $95 \% \mathrm{CI}-10.84$ to $-4.08, P^{2}=0 ; P=0.80$ ). The largest difference occurred 50 minutes after inhalation of Dex (Dex vs control, MD $-10.20 \mathrm{mmHg}, 95 \% \mathrm{CI}-13.75$ to $-6.66, I^{2}=0$; $P=0.84)$. Pooled results showed no significant difference in blood pressure between the two groups at 70 minutes after inhalation of Dex (Dex vs control, MD $-2.73 \mathrm{mmHg}, 95 \%$ CI -8.08 to $2.62, I^{2}=57 \% ; P=0.10$; Table 5).

\section{Pain}

Four articles included in this study evaluated pain at different stages after surgery. Since evaluation time varied greatly, no meta-analysis was performed. Cheung et al noted that compared to the control group, the Dex group reported significant pain relief within 12 hours after surgery (either during mouth opening or at rest). ${ }^{26}$ In addition, Shetty et al suggested that intranasal inhalation of Dex can reduce pain during and after surgery. ${ }^{23}$ Ryu et al confirmed that the pain level of patients can be reduced 1-3 days after surgery by intranasal inhalation of Dex. ${ }^{24}$ However, Nooh et al suggested that intranasal inhalation of Dex did not improve pain after tooth extraction. ${ }^{25}$

\section{Adverse reactions}

Nooh et al reported several postoperative adverse events: six patients in the Dex group developed dry mouth after surgery, one patient had mild tremors, and two patients had mild dizziness. Two patients were reported to have postoperative dry mouth in the control group. ${ }^{25}$ Cheung et al reported that the incidence of postoperative dizziness in the control group was significantly higher than in the Dex group. ${ }^{26}$ Other studies did not report postoperative adverse reactions.

\section{Publication bias}

Results of pooled analysis showed that the funnel plot did not indicate publication bias. 


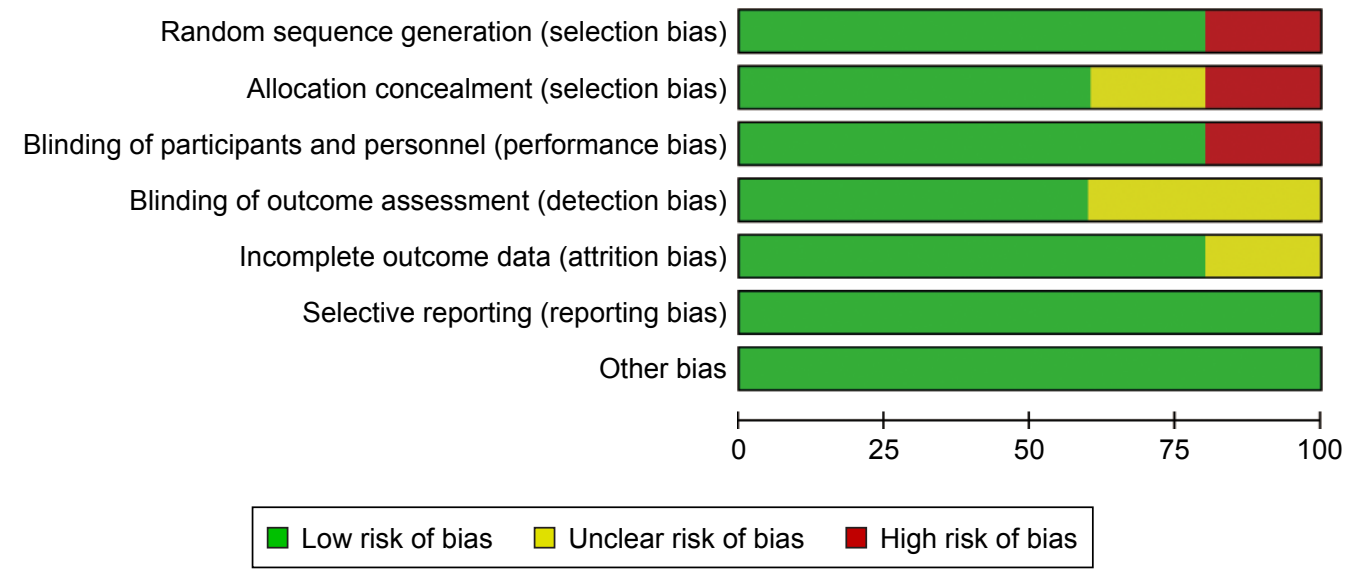

Figure 2 Quality assessment of included studies.

\section{Discussion}

In this systematic review, the five articles included evaluated five indicators (systolic blood pressure, HR, OAA/S, BIS, and pain). Four of these indicators were included in the metaanalysis. In the five articles, the doses in the experimental group were similar and postoperative evaluation methods were consistent. Results of the pooled analysis showed that the funnel plot did not indicate publication bias. Additionally, in this meta-analysis, the sensitivity analysis showed consistent results. Therefore, the pooled results of this metaanalysis are reliable.

Pooled results of the BIS analysis showed that 20 minutes after intranasal inhalation, the BIS value of patients in the Dex group was significantly different from the control group, suggesting a sedated status. The sedative effect was most pronounced at 40 minutes, and lasted until approximately 60 minutes after administration of the drugs. In the five articles, operation time was approximately $20-30$ minutes. Therefore, a single intranasal administration provides patients with a good sedative effect during tooth extraction. Patients returned to the baseline state 90 minutes after drug administration. In addition, three articles used the OAA/S score to evaluate patients' sedation status. Pooled results were similar to those of the BIS. Both findings suggested that a single intranasal administration can ensure a good sedative effect during tooth extraction.

Dex has a certain analgesic effect via the anti-inflammatory and antioxidation pathway. ${ }^{9,15,29,30}$ These results were not included in the meta-analysis, because of the inconsistent evaluation time in the five articles. Dex acts on the $\alpha_{2}$ adrenergic receptor, which inhibits norepinephrine release and sympathetic conduction, causing blood pressure to decrease and HR to slow. ${ }^{31}$ The pooled results of this study suggest that blood pressure and HR values in the Dex group were both

Table 2 Pooled results of OAA/S

\begin{tabular}{|c|c|c|c|c|}
\hline Item & Pooled results & Gu et $\mathbf{a l}^{27}$ & Nooh et $\mathrm{al}^{25}$ & Shetty and Aggarwal ${ }^{23}$ \\
\hline Induction 0 minutes, SMD $(95 \% \mathrm{Cl})$ & $-0.40(-0.99$ to 0.19$)$ & Not estimable & $-0.40(-0.99$ to 0.19$)$ & NR \\
\hline Induction 10 minutes, SMD $(95 \% \mathrm{Cl})$ & $0.04(-0.44$ to 0.53$)$ & $0(-0.72$ to 0.72$)$ & $0.08(-0.57$ to 0.73$)$ & NR \\
\hline Induction 20 minutes, SMD $(95 \% \mathrm{Cl})$ & $-1.20(-1.73 \text { to }-0.67)^{\#}$ & $-1.22(-2.00 \text { to }-0.43)^{\#}$ & $-1.18(-1.90 \text { to }-0.47)^{\#}$ & NR \\
\hline Induction 30 minutes, SMD $(95 \% \mathrm{Cl})$ & $-2.54(-3.10 \text { to }-1.98)^{\#}$ & $-2.36(-3.32 \text { to }-1.40)^{\#}$ & $-2.22(-3.07 \text { to }-1.37)^{\#}$ & $-3.40(-4.56 \text { to }-2.23)^{\#}$ \\
\hline Induction 40 minutes, SMD $(95 \% \mathrm{Cl})$ & $-3.19(-3.95 \text { to }-2.43)^{\#}$ & $-3.58(-4.78 \text { to }-2.37)^{\#}$ & $-2.94(-3.91 \text { to }-1.97)^{\#}$ & NR \\
\hline Induction 50 minutes, SMD $(95 \% \mathrm{Cl})$ & $-2.64(-3.32 \text { to }-1.96)^{\#}$ & $-2.60(-3.60 \text { to }-1.59)^{\#}$ & $-2.67(-3.59 \text { to }-1.75)^{\#}$ & NR \\
\hline Induction 60 minutes, SMD $(95 \% \mathrm{Cl})$ & $-1.65(-2.22 \text { to }-1.08)^{\#}$ & $-1.64(-2.48 \text { to }-0.80)^{\#}$ & $-1.65(-2.42 \text { to }-0.89)^{\#}$ & NR \\
\hline Induction 70 minutes, SMD $(95 \% \mathrm{Cl})$ & $-0.73(-1.23 \text { to }-0.22)^{\#}$ & $-0.43(-1.15$ to 0.30$)$ & $-1.00(-1.70 \text { to }-0.31)^{\#}$ & NR \\
\hline Induction 80 minutes, SMD $(95 \% \mathrm{Cl})$ & $-0.65(-1.43$ to 0.14$)$ & $-0.24(-0.96$ to 0.48$)$ & $-1.04(-1.74 \text { to }-0.34)^{\#}$ & NR \\
\hline Induction 90 minutes, SMD $(95 \% \mathrm{Cl})$ & $-0.26(-0.74$ to 0.23$)$ & $-0.32(-1.05$ to 0.40$)$ & $-0.20(-0.86$ to 0.45$)$ & NR \\
\hline
\end{tabular}

Note: ${ }^{\# P}<0.05$.

Abbreviations: OAA/S, observer assessment of alertness/sedation; NR, not reported; SMD, standardized mean difference. 

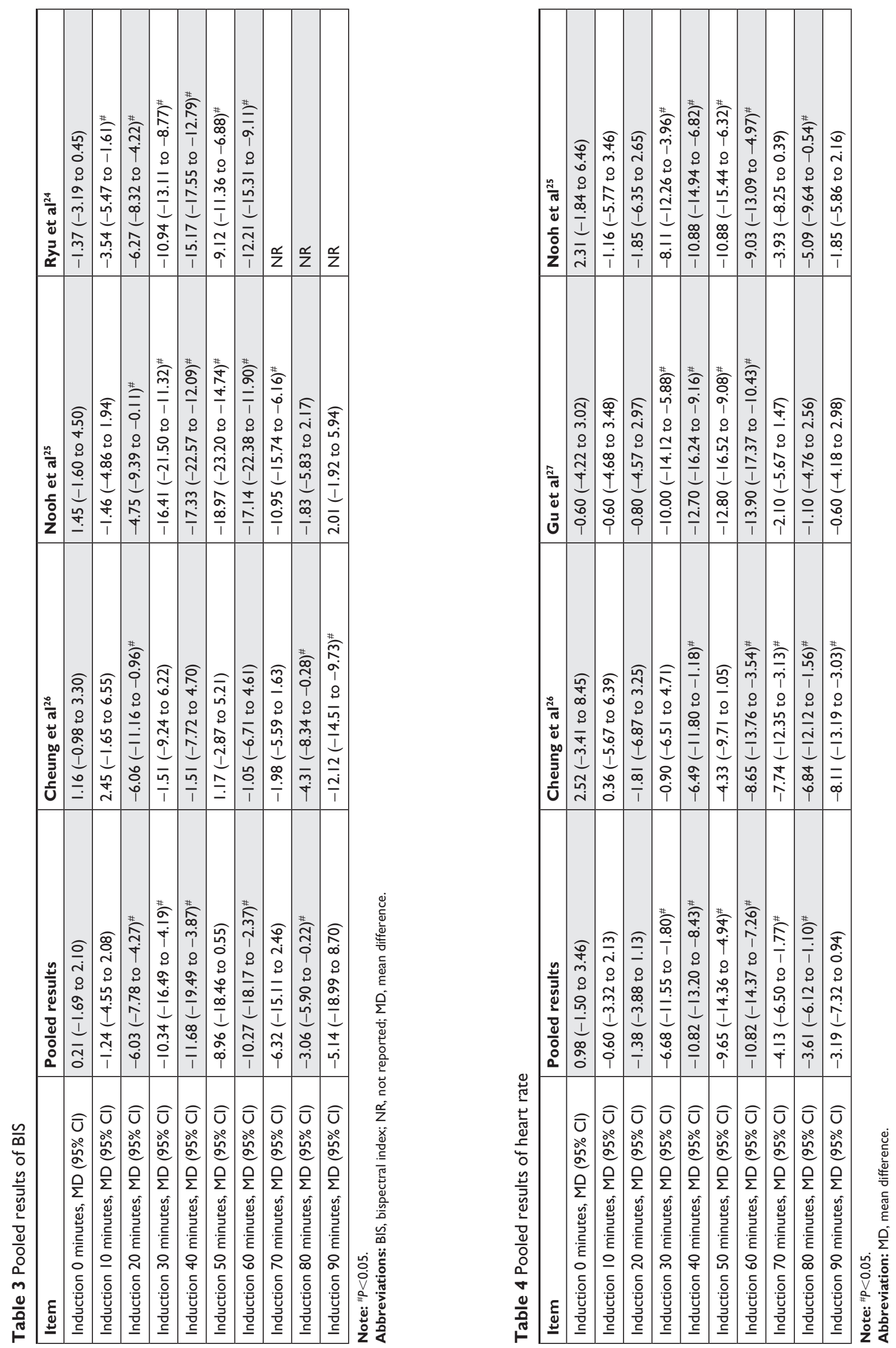
Table 5 Pooled results of systolic blood pressure

\begin{tabular}{|c|c|c|c|c|}
\hline Item & Pooled results & Cheung et $\mathrm{al}^{26}$ & Gu et $\mathbf{a l}^{27}$ & Nooh et $\mathrm{al}^{25}$ \\
\hline Induction 0 minutes, $\mathrm{MD}(95 \% \mathrm{Cl})$ & $-1.81(-5.10$ to 1.49$)$ & $-2.19(-7.88$ to 3.50$)$ & $-0.80(-5.60$ to 4.00$)$ & $-3.60(-11.09$ to 3.89$)$ \\
\hline Induction 10 minutes, MD $(95 \% \mathrm{Cl})$ & $-1.28(-4.30$ to 1.75$)$ & $-2.20(-7.00$ to 2.60$)$ & $-0.40(-5.02$ to 4.22$)$ & $-1.32(-8.59$ to 5.95$)$ \\
\hline Induction 20 minutes, $\mathrm{MD}(95 \% \mathrm{Cl})$ & $-3.05(-6.24$ to 0.15$)$ & $-3.83(-8.43$ to 0.77$)$ & $-2.00(-7.12$ to 3.12$)$ & $-3.27(-12.19$ to 5.65$)$ \\
\hline Induction 30 minutes, $\mathrm{MD}(95 \% \mathrm{Cl})$ & $-7.46(-10.84 \text { to }-4.08)^{\#}$ & $-6.20(-11.23 \text { to }-1.17)^{\#}$ & $-8.40(-13.62 \text { to }-3.18)^{\#}$ & $-8.83(-18.22$ to 0.56$)$ \\
\hline Induction 40 minutes, $\mathrm{MD}(95 \% \mathrm{Cl})$ & $-9.36(-13.10 \text { to }-5.62)^{\#}$ & $-8.20(-15.97 \text { to }-0.43)^{\#}$ & $-8.80(-13.92 \text { to }-3.68)^{\#}$ & $-11.78(-19.50 \text { to }-4.06)^{\#}$ \\
\hline Induction 50 minutes, $\mathrm{MD}(95 \% \mathrm{Cl})$ & $-10.20(-13.75 \text { to }-6.66)^{\#}$ & $-9.30(-15.90 \text { to }-2.70)^{\#}$ & $-9.80(-14.96 \text { to }-4.64)^{\#}$ & $-12.10(-19.36 \text { to }-4.84)^{\#}$ \\
\hline Induction 60 minutes, $\mathrm{MD}(95 \% \mathrm{Cl})$ & $-8.77(-12.49 \text { to }-5.05)^{\#}$ & $-7.66(-15.81$ to 0.49$)$ & $-8.50(-13.66 \text { to }-3.34)^{\#}$ & $-10.14(-17.28 \text { to }-3.00)^{\#}$ \\
\hline Induction 70 minutes, $\mathrm{MD}(95 \% \mathrm{Cl})$ & -2.73 (-8.08 to 2.62$)$ & $-7.84(-13.5 \mid \text { to }-2.17)^{\#}$ & $-0.60(-5.82$ to 4.62$)$ & $0.97(-6.58$ to 8.52$)$ \\
\hline Induction 80 minutes, $\mathrm{MD}(95 \% \mathrm{Cl})$ & $-4.26(-11.86$ to 3.35$)$ & $-11.85(-17.47$ to -6.23$)$ & $-0.20(-5.18$ to 4.78$)$ & $-0.66(-7.23$ to 5.91$)$ \\
\hline Induction 90 minutes, $\mathrm{MD}(95 \% \mathrm{Cl})$ & $-6.06(-16.08$ to 3.95$)$ & $-15.49(-21.19$ to -9.79$)$ & $-2.29(-9.82$ to 5.24$)$ & $-0.20(-5.58$ to 5.18$)$ \\
\hline
\end{tabular}

Note: ${ }^{*} P<0.05$.

Abbreviation: MD, mean difference.

significantly lower than those in the control group 30 minutes after intranasal administration. The largest difference occurred 40-50 minutes after drug administration, but differences did not exceed $20 \%$ of the baseline value. It is suggested that this drug should be used with caution in patients with slow HR and low blood pressure. ${ }^{32,33}$ Patient blood pressure and HR returned to baseline 90 minutes after drug administration, which is consistent with previous literature reports. ${ }^{34}$

Interestingly, mixing lidocaine with Dex can enhance the anesthesia effect and duration of lidocaine anesthesia in mandibular nerve-block anesthesia, and the effect is dose-dependent. ${ }^{35,36}$ Unfortunately, the five articles here did not evaluate differences in anesthetic effects of mandibular nerve-block anesthesia in the Dex and control groups.

The most commonly used drug for clinical sedation is midazolam, which has sedation, hypnosis, antianxiety, and anterograde-amnesia effects. Studies have shown that intravenous injection of Dex produces a sedative effect similar to midazolam during third molar extraction. ${ }^{37,38}$ An intranasal spray can produce local therapeutic effects or systemic therapeutic effects through nasal mucosa absorption. ${ }^{39}$ This method has the advantages of convenient use, accurate administration, uniform distribution, and low dose ${ }^{40}$ However, a study found that intranasal administration of midazolam can cause adverse reactions, such as nasal mucosal irritation; therefore, it is not suitable for intranasal administration..$^{41-43}$ Dex is a highly selective $\alpha_{2}$ adrenergic receptor agonist. It is colorless and odorless and does not irritate the nasal mucosa, which is ideal for intranasal administration. ${ }^{44}$ Additionally, Ryu et al compared the use of intravenous and intranasal administration of Dex in third molar surgery, and showed that the two modes of administration produced similar sedative effects..$^{24}$ As a noninvasive method of administration, intranasal inhalation of Dex can produce good sedative effects and can be applied to dental patients with preoperative anxiety.

There are limitations of this systematic evaluation. The articles included described slight variations in the dose administered, difficulty of tooth extraction, and operation time. Regarding the administered dose, only one article applied $1 \mu \mathrm{g}$ and the others $1.5 \mu \mathrm{g}$. Time for tooth extraction was generally $20-30$ minutes, suggesting that extraction difficulty was similar among studies. However, impaction type was not explained in detail in the articles. The number of samples included was small: only 363 patients were included. Follow-up time was short in the articles, and adverse reactions and pain levels during the first a few days after surgery were not recorded, which prevented evaluation of the analgesic effect of intranasal inhalation of Dex. Subjects in the articles were all Asians. Therefore, in future, a rigorous multicenter, large-sample RCT should be designed to verify our conclusions.

\section{Conclusion}

Intranasal inhalation of Dex 30 minutes before third molar extraction can produce a good sedative effect and a certain degree of postoperative analgesia, and large-sample, multicenter RCTs are needed to evaluate the analgesic effect of Dex.

\section{Acknowledgment}

Tingting Yu and Huaqiang Zhao are to be considered cocorrespondence authors.

\section{Disclosure}

The authors report no conflicts of interest in this work. 


\section{References}

1. Breik O, Grubor D. The incidence of mandibular third molar impactions in different skeletal face types. Aust Dent J. 2008;53(4):320-324. doi:10.1111/j.1834-7819.2008.00073.x

2. Slade GD, Foy SP, Shugars DA, Phillips C, White RP. The impact of third molar symptoms, pain, and swelling on oral health-related quality of life. J Oral Maxillofac Surg. 2004;62(9):1118-1124.

3. Carter K, Worthington S. Predictors of third molar impaction: a systematic review and meta-analysis. J Dent Res. 2016;95(3):267-276. doi: $10.1177 / 0022034515615857$

4. Tanidir AN, Atac MS, Karacelebi E. Information given by multimedia: influence on anxiety about extraction of impacted wisdom teeth. Br J Oral Maxillofac Surg. 2016;54(6):652-657. doi:10.1016/j.bjoms. 2016.03.026

5. Lenk M, Berth H, Joraschky P, Petrowski K, Weidner K, Hannig C. Fear of dental treatment - an underrecognized symptom in people with impaired mental health. Dtsch Arztebl Int. 2013;110(31-32):517-522. doi:10.3238/arztebl.2013.0517

6. Astramskaitė I, Poškevičius L, Juodžbalys G. Factors determining tooth extraction anxiety and fear in adult dental patients: a systematic review. Int J Oral Max Surg. 2016;45(12):1630-1643. doi:10.1016/j. ijom.2016.06.019

7. Brignardello-Petersen R. Previous bad experience, propensity to anxiety, and pain expectations may be associated with fear and anxiety when undergoing tooth extractions. J Am Dent Assoc. 2017;148(4):e4. doi:10.1016/j.adaj.2016.11.015

8. Gerlach AT, Dasta JF. Dexmedetomidine: an updated review. Ann Pharmacother. 2007;41(2):245-252.

9. Hoy SM, Keating GM. Dexmedetomidine: a review of its use for sedation in mechanically ventilated patients in an intensive care setting and for procedural sedation. Drugs. 2011;71(11):1481-1501. doi:10.2165/ 11207190-000000000-00000

10. Davoudi A, Movahedian AB, Shadmehr E. Risks and benefits of pre-operative dexmedetomidine in oral and maxillofacial surgeries: a systematic review. Expert Opin Drug Saf. 2017;16(6):711-720. doi:10.1080/14740338.2017.1323865

11. Chandanwale A, Langade D, Sonawane D, Gavai P. A randomized, clinical trial to evaluate efficacy and tolerability of trypsin: chymotrypsinas compared to serratiopeptidase and trypsin: bromelain:rutosidein wound management. Adv Ther. 2017;34(1):180-198. doi:10.1007/ s12325-016-0444-0

12. Bhagat S, Agarwal M, Roy V. Serratiopeptidase: a systematic review of the existing evidence. Int J Surg. 2013;11(3):209-217. doi:10.1016/j. ijsu.2013.01.010

13. Rana M, Gellrich NC, Joos U, Piffkó J, Kater W. 3D evaluation of postoperative swelling using two different cooling methods following orthognathic surgery: a randomised observer blind prospective pilot study. Int J Oral Maxillofac Surg. 2011;40(7):690-696. doi:10.1016/j.ijom. 2011.02 .015

14. Tachibana M, Mizukoshi O, Harada Y, Kawamoto K, Nakai Y. A multi-centre, double-blind study of serrapeptase versus placebo in postantrotomy buccal swelling. Pharmatherapeutica. 1984;3(8):526-530.

15. Cheung CW, Ng KF, Choi WS, Chiu WK, Ying CL, Irwin MG. Evaluation of the analgesic efficacy of local dexmedetomidine application. Clin J Pain. 2011;27(5):377-382. doi:10.1097/AJP.0b013e318208c8c5

16. Jun JH, Kim KN, Kim JY, Song SM. The effects of intranasal dexmedetomidine premedication in children: a systematic review and meta-analysis. Can J Anaesth. 2017;64(9):947-961. doi:10.1007/s12630017-0917-x

17. Yuen VM, Hui TW, Irwin MG, Yuen MK. A comparison of intranasal dexmedetomidine and oral midazolam for premedication in pediatric anesthesia: a double-blinded randomized controlled trial. Anesth Analg. 2008;106(6):1715-1721. doi:10.1213/ane.0b013e31816c8929

18. Higgins JP, Altman DG, Gøtzsche PC, et al. The Cochrane Collaboration's tool for assessing risk of bias in randomised trials. BMJ. 2011; 343:d5928. doi:10.1136/bmj.d5928
19. Higgins JP, Green S. Cochrane handbook for systematic reviews of interventions 9.2.3 [updated March 2011]. Cochrane Library 2011.

20. Koletsi D, Fleming PS, Michelaki I, Pandis N. Heterogeneity in Cochrane and non-Cochrane meta-analyses in orthodontics. J Dent. 2018; 74(undefined):90-94. doi:10.1016/j.jdent.2018.05.003

21. van den Ende CH, Cornelia HM, Esther MJ, Steultjens EM, Lex M. Clinical heterogeneity was a common problem in Cochrane reviews of physiotherapy and occupational therapy. J Clin Epidemiol. 2006;59(9): 914-919. doi:10.1016/j.jclinepi.2005.12.014

22. Langan D, Higgins JP, Gregory W, Sutton AJ. Graphical augmentations to the funnel plot assess the impact of additional evidence on a meta-analysis. J Clin Epidemiol. 2012;65(5):511-519. doi:10.1016/j. jclinepi.2011.10.009

23. Shetty SK, Aggarwal G. Efficacy of intranasal dexmedetomidine for conscious sedation in patients undergoing surgical removal of impacted third molar: a double-blind split mouth study. J Maxillofac Oral Surg. 2016;15(4):512-516. doi:10.1007/s12663-016-0889-3

24. Ryu DS, Lee DW, Choi SC, Oh IH. Sedation protocol using dexmedetomidine for third molar extraction. J Oral Maxillofac Surg. 2016; 74(5):921-926. doi:10.1016/j.joms.2015.12.021

25. Nooh N, Sheta SA, Abdullah WA, Abdelhalim AA. Intranasal atomized dexmedetomidine for sedation during third molar extraction. Int J Oral Maxillofac Surg. 2013;42(7):857-862.

26. Cheung $\mathrm{CW}, \mathrm{Ng} \mathrm{KF}$, Liu J, Yuen MY, Ho MH, Irwin MG. Analgesic and sedative effects of intranasal dexmedetomidine in third molar surgery under local anaesthesia. Brit J Anaesth. 2011;107(3): $430-437$.

27. Gu CM, Zhong YP, Huang LZ, Shi YH. Sedative and analgesic effects of intranasal dexmedetomidine in mandibular third molar extraction. J Oral Maxillofac Surg. 2014;24(3):220.

28. March PA, Muir WW. Bispectral analysis of the electroencephalogram: a review of its development and use in anesthesia. Vet Anaesth Analg. 2005;32(5):241-255. doi:10.1111/j.1467-2995.2005.00221.x

29. Li S, Yang Y, Yu C, et al. Dexmedetomidine analgesia effects in patients undergoing dental implant surgery and its impact on postoperative inflammatory and oxidative stress. Oxid Med Cell Longev. 2015;1-11. doi: $10.1155 / 2015 / 186736$

30. Cheung CW, Ng KF, Choi WS, Chiu WK, Ying CL, Irwin MG. Evaluation of the analgesic efficacy of local dexmedetomidine application. Clin J Pain. 2011;(5):377-382. doi:10.1097/AJP.0b013e318208c8c5

31. Keating GM. Dexmedetomidine: a review of its use for sedation in the intensive care setting. Drugs. 2015;75(10):1119-1130. doi:10.1007/ s40265-015-0419-5

32. Sichrovsky TC, Mittal S, Steinberg JS. Dexmedetomidine sedation leading to refractory cardiogenic shock. Anesth Analg. 2008;106(6): 1784-1786. doi:10.1213/ane.0b013e318172fafc

33. Tobias JD, Gupta P, Naguib A, Yates AR. Dexmedetomidine: applications for the pediatric patient with congenital heart disease. Pediatr Cardiol. 2011;32(8):1075-1087. doi:10.1007/s00246-011-0092-8

34. Weerink MA, Struys MM, Hannivoort LN, Barends CR, Absalom AR, Colin P. Clinical pharmacokinetics and pharmacodynamics of dexmedetomidine. Clin Pharmacokinet. 2017;56(8):893-913. doi:10.1007/ s40262-017-0507-7

35. Ouchi K, Sugiyama K. Dexmedetomidine dose dependently enhances the local anesthetic action of lidocaine in inferior alveolar nerve block: a randomized double-blind study. Reg Anesth Pain Med. 2016;41(3): 348-355. doi:10.1097/AAP.0000000000000380

36. Singh V, Thepra M, Kirti S, Kumar P, Priya K. Dexmedetomidine as an additive to local anesthesia: a step to development in dentistry. J Oral Maxillofac Surg. 2018;76(10):2091. doi:10.1016/j.joms.2018.05.037

37. Cheung CW, Ying CL, Chiu WK, Wong GT, Ng KF. A comparison of dexmedetomidine and midazolam for sedation in third molar surgery. Anaesthesia. 2007;62(11):1132-1138. doi:10.1111/j.1365-2044.2007.05230.x

38. Fawzy K, Eldeen AE, Said-Ahmed HA. A comparative study of dexmedetomidine and midazolam for third molar extraction under conscious sedation using bispectral index system. Acta Anaesthesiol Ital. 2007;58(2):164. 
39. Krauland AH, Leitner VM, Grabovac V, Bernkop-Schnürch A. In vivo evaluation of a nasal insulin delivery system based on thiolated chitosan. J Pharm Sci. 2006;95(11):2463-2472. doi:10.1002/ jps. 20700

40. Sintov AC, Levy HV, Botner S. Systemic delivery of insulin via the nasal route using a new microemulsion system: in vitro and in vivo studies. J Control Release. 2010;148(2):168-176. doi:10.1016/j.jconrel. 2010.08.004

41. Deshmukh PV, Kulkarni SS, Parchandekar MK, Sikchi SP. Comparison of preanesthetic sedation in pediatric patients with oral and intranasal midazolam. J Anaesthesiol Clin Pharmacol. 2016;32(3):353-358. doi:10.4103/0970-9185.168205
42. Knoester PD, Jonker DM, van der Hoeven RT, et al. Pharmacokinetics and pharmacodynamics of midazolam administered as a concentrated intranasal spray. A study in healthy volunteers. Brit J Clin Pharmacol. 2002;53(5):501-507. doi:10.1046/j.1365-2125.2002.01588.x

43. Dale $\mathrm{O}$, Nilsen $\mathrm{T}$, Loftsson $\mathrm{T}$, et al. Intranasal midazolam: a comparison of two delivery devices in human volunteers. J Pharm Pharmacol. 2006;58(10):1311-1318. doi:10.1211/jpp.58.10.0003

44. Li A, Yuen VM, Goulay-Dufaÿ S, et al. Pharmacokinetic and pharmacodynamic study of intranasal and intravenous dexmedetomidine. Br J Anaesth. 2018;120(5):960-968. doi:10.1016/j.bja.2017.11.100 


\section{Supplementary material Search strategies \\ Cochrane}

\#1: Molars, third: ti, ab, kw or "third molar": ti, ab, kw or "third molars": ti, ab, kw or "tooth, wisdom": ti, ab, kw or "wisdom tooth": ti, ab, kw or "teeth, wisdom": ti, ab, kw or "wisdom teeth": ti, ab, kw or "molar, third": ti, ab, kw or "tooth, impacted": ti, ab, kw or "impacted teeth": ti, ab, kw or "impacted tooth": ti, ab, kw or "teeth impacted" $(2,432)$ \#2: PV-1440: ti, ab, kw or "MPV 1440": ti, ab, kw or "MPV1440": ti, ab, kw or "Precedex": ti, ab, kw or "Hospira brand of dexmedetomidine hydrochloride": ti, ab, kw or "dexmedetomidine hydrochloride": ti, ab, kw or "hydrochloride, dexmedetomidine": ti, ab, kw or "dexmedetomidine" $(2,545)$ \#3: \#1 AND \#2 (13)

\section{Web of Science}

\#1: TS = (molars, third OR third molar OR third molars OR tooth, wisdom OR wisdom tooth OR teeth, wisdom OR wisdom teeth OR molar, third OR tooth, impacted OR impacted teeth OR impacted tooth OR teeth impacted) $(31,537)$
\#2: TS = (MPV-1440 OR MPV 1440 OR MPV1440 OR Precedex OR dexmedetomidine hydrochloride OR hydrochloride, dexmedetomidine OR dexmedetomidine) $(8,195)$ \#3: \#1 AND \#2 (18)

\section{PubMed}

\#1: “dexmedetomidine”[MeSH] $(2,814)$

\#2: (MPV-1440[Title/Abstract]) OR (MPV 1440[Title/ Abstract]) OR (MPV1440[Title/Abstract]) OR (Precedex[Title/Abstract]) OR (Dexmedetomidine Hydrochloride[Title/Abstract]) OR (Hydrochloride, Dexmedetomidine[Title/Abstract]) (105)

\#3: \#1 or \#2 $(2,855)$

\#4: "molar, third"[MeSH] $(5,893)$

\#5: (Molars, Third[Title/Abstract]) OR (Third Molar[Title/ Abstract]) OR (Third Molars[Title/Abstract]) OR (Tooth, Wisdom[Title/Abstract]) OR (Wisdom Tooth[Title/ Abstract]) OR (Teeth, Wisdom[Title/Abstract]) OR (Wisdom Teeth[Title/Abstract]) (11613)

\#6: \#4 or \#5 (11,935)

\#7: \#3 and \#6 (11)
Drug Design, Development and Therapy

\section{Publish your work in this journal}

Drug Design, Development and Therapy is an international, peerreviewed open-access journal that spans the spectrum of drug design and development through to clinical applications. Clinical outcomes, patient safety, and programs for the development and effective, safe, and sustained use of medicines are the features of the journal, which

\section{Dovepress}

has also been accepted for indexing on PubMed Central. The manuscript management system is completely online and includes a very quick and fair peer-review system, which is all easy to use. Visit http://www.dovepress.com/testimonials.php to read real quotes from published authors. 